\title{
THE SMART PROMISE
}

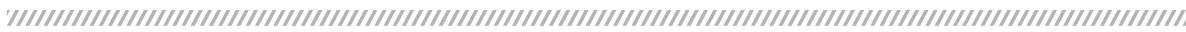

Dear Readers,

In the first phase of Prime Minister Narendra Modi’s grand vision of setting up 100 smart cities in the country, an amount of ` 50,802 cr has now been lined up for investment in 20 selected cities over the next five years. These cities are projected to offer good quality of life to the citizens through smart solutions. Assured power and water supply, adequate sanitation and solid waste management, connected solutions through the use of internet, e-governance and an efficient urban mobility and public transport system are top on the government's agenda.

In the current context, the Indian transport infrastructure is hugely inadequate. While the demand for a sustainable solution to the urban mobility woes has been doing the rounds for years, any integrated approach has yet not seen the light of the day. In fact, a 'smart' city can benefit tremendously from enhanced mobility and transportation solutions, including reduced congestion, improved air pollution, shorter times spent on the road and increased productivity.

I believe there is promise in the thought of developing smart cities in India. This idea, together with the rightful implementation of the National Electric Mobility Mission Plan 2020, might just be the right mix for finding solutions to the urban nightmares in our country currently. That a step has been taken towards creating urban spaces that would be environmentally-friendly and technologically integrated to improve speed and efficiency is positive, and welcome.

That said, rapid urbanisation and increasing population means mobility will continue to be one of the toughest challenges for cities world over. The usual practice thus far has been to add new capacities in city infrastructure to accommodate the demand, but experts believe that approach is not sustainable in the long-run. Future mobility demands seamless travel, with services available at the click of a button or better still, a touch. A city will be smart when technology becomes an enabler - for its citizens and for the system - not just in physical terms, but also in operational terms.

There is serious intent in the government's drive to make our cities smart. It's for the other stakeholders now to raise their hands up and deliver.
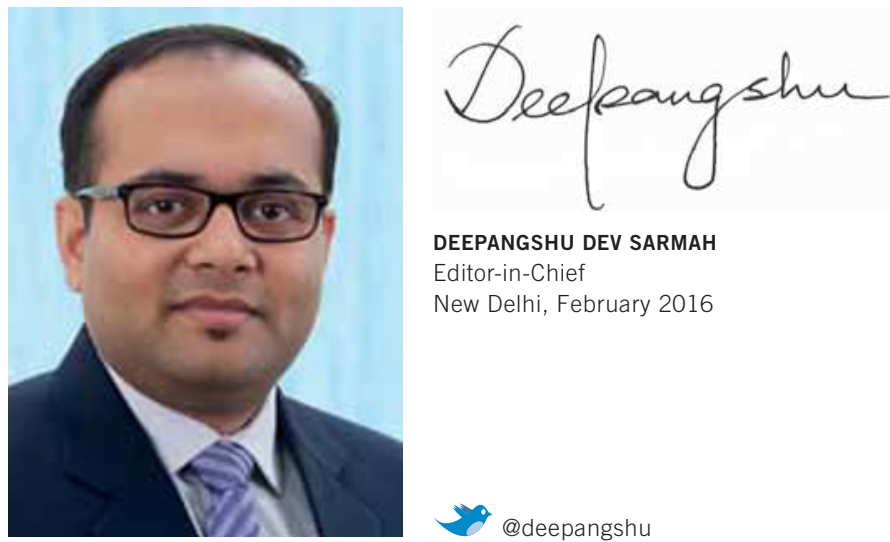

DEEPANGSHU DEV SARMAH

Editor-in-Chief

New Delhi, February 2016 